\title{
CONSIDERAÇÕES SOBRE A ORIGEM E O SIGNIFICADO, EM PROSPECCCÃO MINERAL, DOS VEIOS GIGANTES DE QUARTZO EM GRANITÓIDES DO MACIÇO CATAS ALTAS NO SUDESTE DO ESTADO DE SÃO PAULO
}

\author{
Paulo César PRESSINOTTI*
}

\begin{abstract}
RESUMO
Veios gigantes de quartzo foram identificados em zonas de descontinuidade estrutural, em granitóides do Maciço Catas Altas, no sudeste do Estado de São Paulo. Considerando seu possível caráter hidrotermal, trabalhos prospectivos foram efetuados em algumas áreas portadoras destes veios, para se definir o potencial mineral. Como resultado, foram identificadas concentrações anômalas de W, Sn, F e Ba nos granitóides, sendo que algumas dessas concentrações estão sendo objeto de detalhamento.
\end{abstract}

\section{ABSTRACT}

Giant quartz vein hosted along faults in granitoids, were identified in Catas Altas Massif, State of São Paulo, Brazil. Supposing hidrothermal character of these veins, geological reconnaissance was done to evaluate the mineral potential in the granitoids areas. As a result some epigenetic ocorrences of W, Sn, F and Ba were detected. Although no detailed study of these veins related with the spatially associated mineralization was done, it is suggested to use the giant quartz veins as a guide prospection.

\section{INTRODUÇÃO}

A presente nota foi obtida a partir de trabalhos de prospecção regional, realizados pelo Agrupamento de Recursos Minerais do Instituto de Pesquisas Tecnológicas do Estado de São Paulo S.A. (IPT) para a Secretaria de Ciência e Tecnologia do Estado de São Paulo (SCT), Programa de Desenvolvimento de Recursos Minerais (Pró-Minério).

Durante os levantamentos de campo efetuados nos granitóides do Maciço Catas Altas no sudeste do Estado de São Paulo - com a finalidade de selecionar alvos potenciais passíveis de conterem mineralizações epigenéticas, F, Sn, W foram detectados veios gigantes de quartzo (extensão de algumas centenas de metros e espessura métrica, 1 a 10 metros), os quais se constituem no enfoque principal deste trabalho.

Como objetivo, pretende-se, além de apontar a presença de alguns destes veios, apresentar uma breve discussão sobre sua origem e seu significado em prospecção mineral.

\section{HISTÓRICO}

Veios gigantes de quartzo (V.G.Q.), com disseminações de barita e galena, alojados nos granitóides Três Córregos, próximo ao ribeirão das Criminosas, município de Ribeirão-SP, e nos granitóides Mandira em Cananéia-SP, foram apontados por Rubens Borges da Silva em IPT (1984). Tais veios gigantes foram interpretados como originados pela atuação de células de convecção em áreas de gradiente geotérmico elevado.

Trabalhos de prospecção regional, IPT (1986), visando selecionar alvos potenciais passíveis de conterem mineralizações epigenéticas de fluorita, nos granitóides Três Córregos, tiveram como um de seus critérios prospectivos a verificação em termos regionais de presença 
destes veios, haja vista a aplicação do modelo de células de convecção, agente responsável pelas mineralizações de fluorita na província de Santa Catarina, DARDENNE \& SAVI (1984); IPT (1984). Neste sentido, através de interpretação fotogeológica acompanhada de reconhecimento de campo, pode-se constatar a presença de outros veios, alojados em zonas de fraqueza estrutural, desenvolvidos, freqüentemente, em granitóides (vide FIGURA 1).

\section{ASPECTOS GERAIS DOS VEIOS GIGANTES DE QUARTZO}

Morfologia - Estes veios destacamse morfologicamente por sustentarem espigões retilíneos de cristas agudas, nos quais blocos de quartzo de dimensões métricas alinham-se na direção estrutural do veio. Suas encostas são íngremes e nelas não se desenvolve drenagem.

Petrografia - Petrograficamente, estes veios constituem-se de uma massa de sílica microcristalina e/ou quartzo, entrecortada por vênulas quartzosas irregulares e entrecruzadas. Além dos veios puramente silicosos, podem-se reconhecer as seguintes associações em relação à presença de outros minerais presentes:

a) veios com disseminações de barita e/ou barita e galena;

b) veio cisalhado com especularita em fraturas; e

c) pirita finamente disseminada, que ocorre preferencialmente na presença de sílica microcristalina.

\section{ORIGEM E IMPORTÂNCIA PROSPECTIVA DESTES VEIOS}

A formação dos veios gigantes de quartzo, alojados em zonas de falha, ou seja, zonas permeáveis à circulação de fluidos, pode ser interpretada à luz do modelo de origem hidrotermal e epigenética. De acordo com este modelo, os fluidos migram através de fraturas em áreas de gradiente geotérmico elevado e, em determinado nível, com a diminuição de temperatura e variação de outros fatores (zona de mistura com águas superficiais?), os materiais transportados são depositados nas paredes da fratura. De acordo com FYFE et alii (1978), veios de quartzo de considerável extensão (mui- tas centenas de metros) e espessura ( $1 \mathrm{ou}$ mais metros) são quase invariavelmente de origem hidrotermal.

A importância destes veios, embora de natureza predominante silicosa, reside na suposição de sua origem hidrotermal. Constitui-se, neste caso, num forte argumento que células convectivas atuaram numa determinada área mobilizando e depositando notadamente sílica. Células convectivas também podem eventualmente lixiviar e/ou servir de veículo no transporte de outros elementos químicos è, dessa forma, virem a proporcionar possíveis concentrações minerais.

\section{A IMPORTÂNCIA DOS VEIOS GIGANTES DE QUARTZO NOS GRANITÓIDES DO MACIÇO CATAS ALTAS}

Trabalhos de pesquisa mineral, realizados nos granitóides portadores destes veios, possibilitaram, por vezes, a constatação de terrenos férteis em relação a algumas ocorrências minerais. Analisando-se conjuntamente estas ocorrências minerais e o veio espacialmente associado, podem-se estabelecer as seguintes correlações:

a) V.G.Q. alojados em granitóides portadores de quartzo-topázio-micagreisen, onde foram detectadas interessantes ocorrências de wolframita e cassiterita em coluviões e aluviões atuais;

b) V.G.Q. com ou sem disseminação de barita e/ou barita e galena, alojados em granitóides hospedeiros de mineralizações filoneanas de barita;

c) V.G.Q. com passagem lateral para ocorrência de fluorita cripto a microcristalina associada com calcedônia e epidoto em brecha granítica; $\mathrm{e}$

d) V.G.Q. em granitóides estéreis?!

Além dessas associações, que foram reconhecidas nos granitóides do Maciço Catas Altas, podem-se citar V.G.Q. nos granitóides Mandira, os quais são portadores de ocorrências de sulfetos polimetálicos e disseminações de cassiterita.

Embora o significado destes veios com as mineralizações citadas não tenha sido objeto de estudo mais profundo, o número de ocorrências minerais nos granitóides portadores destes veios é estaticamente interessante, de forma a propiciar a presença destes veios como um 


\section{LOCALIZAÇĀO DOS VEIOS GIGANTES DE QUARTZO}

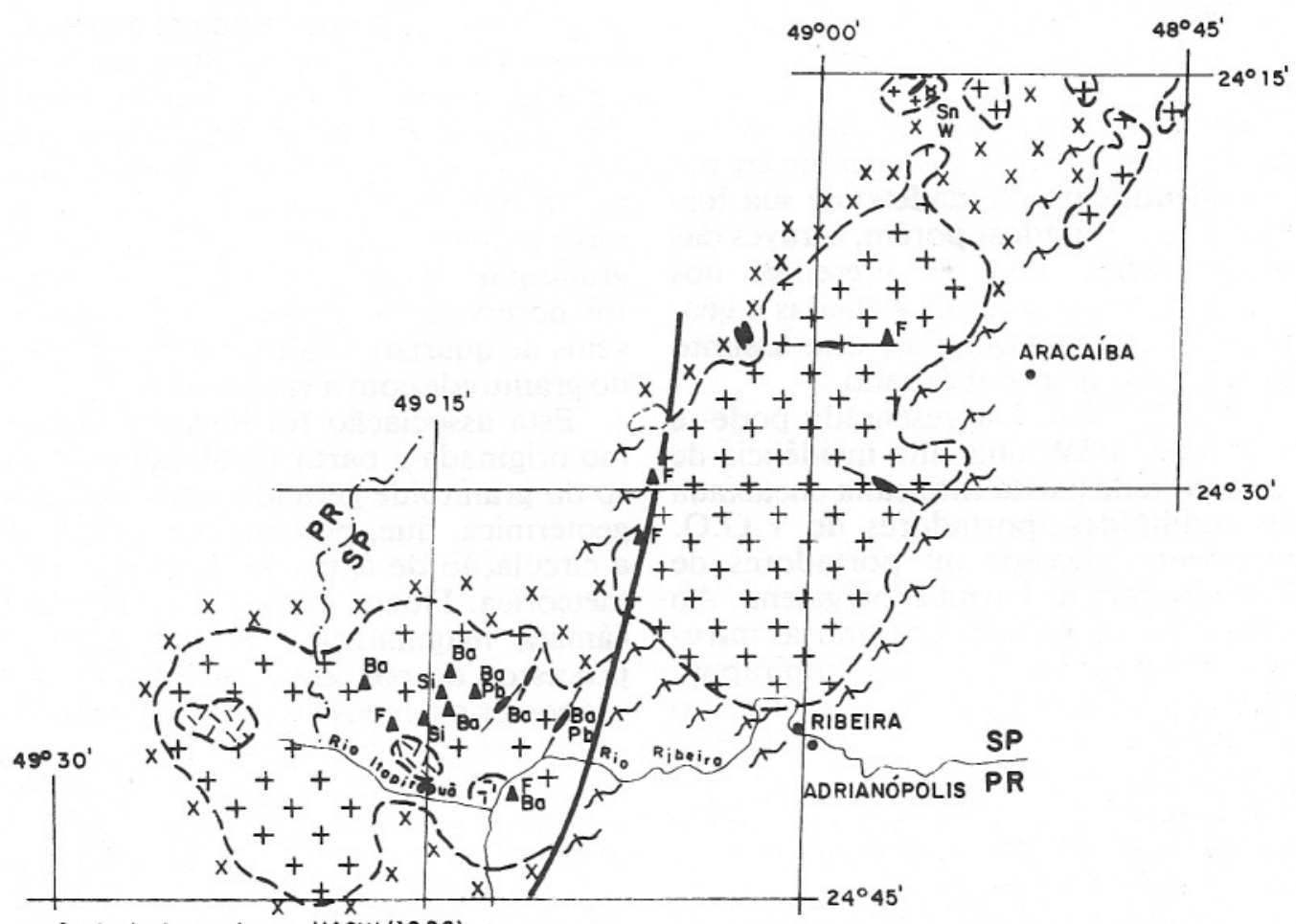

Geologio boseodo em HASUI,(1986)

com odaptaçōes

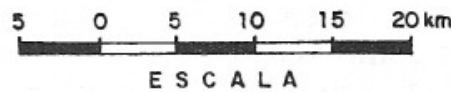

LE G N D A

ES C A L A

\section{MESOZÓı́CO}

E!!! Intrusivas alcalinas

PROTEROZÓICO SUPERIOR-EO-PALEOZÓICO

$+_{+}^{+}$Granito anorogēnico

PROTEROZÓICO MÉDIO A SUPERIOR

$++\quad$ Intrusivos gronitóides

ARQUEANO

Su Suro crostais vulcano-

sedimentores do $\mathrm{Gr}$. Ribeira

${ }^{x} x^{x}$ Complexo Apiai-Mirim
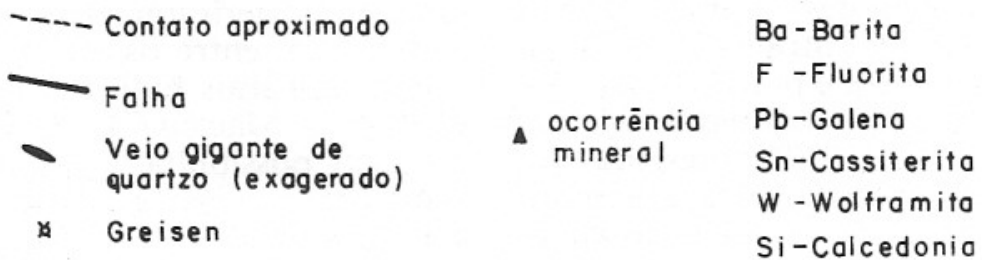

FIGURA I 
guia de prospecção de mineralizações epigenéticas.

\section{DISCUSSÃO SOBRE O MAGMATISMO E OS VEIOS GIGANTES DE QUARTZO}

Estando estes veios alojados em zonas de falha, os critérios disponíveis para se identificar a(s) idade(s) de sua formação são limitados; porém, através das concentrações minerais presentes nos veios e/ou nos granitóides aliadas à geologia da área em questão, este assunto será tentativamente abordado.

Na FIGURA 1 apresentada pode-se reconhecer a SW uma alta incidência de ocorrência de barita filoneana encaixada em granitóides, portadores de V.G.Q. puramente silicosos ou portadores de disseminações de barita e/ou galena. Ao sul desta área, passam a aflorar as intrusivas alcalinas de Barra do Itapirapuã, Itapirapuã e Banhadão, e ainda mais ao sul tem-se as intrusivas alcalinas de Sete Quedas, Barra do Teixeira e Mato Preto. E presumível que o gradiente geotérmico estabelecido por este magmatismo alcalino Mesozóico tenha propiciado a geração de células convectivas, as quais poderiam eventualmente lixiviar e/ou servir como veículo de transporte dos fluidos responsáveis pelas mineralizações filoneanas de barita e dos V.G.Q. em foco. A ocorrência de barita e galena, nas intrusivas alcalinas, e a disseminação desses minerais nos V.G.Q. na área em questão, vêm fortalecer esta hipótese.

A FIGURA 2 é uma adaptação de IPT (1984) e corresponde a um diagrama esquemático, assinalando o grande fluxo de calor em função do magmatismo alcalino que atuou na área, e supostas situações de geração de células convectivas. As situações I e II representam possíveis situações de circulação de fluidos; o caso I proceder-se-ia mais à superfície e envolveria predominantemente a circulação de água meteórica. Passando para profundidades maiores, caso II, ter-se-ia circulação de fluidos através do embasamento subvulcânico, e por fim uma contribuição mais direta de fluidos magmáticos. SILLITOE (1977) apresenta três modelos de geração de veios epitermais em rochas vulcânicas envolvendo circulação de água meteórica e fluidos magmáticos.
Uma outra fase possível de formação destes veios está filiada ao magmatismo granítico anorogênico estabelecido entre o final do Proterozóico Superior e o Eopaleozóico. Esta possibilidade é apontada devido à presença destes veios em porções alteradas metassomaticamente em granitóides com características anorogênicas. Foi reconhecido como produto de alteração a associação quartzotopázio-mica-greisen e albitização no granitóide (vide FIGURA 1). Também foi observada a presença de possantes veios de quartzo "balizando" o contato do granitóide com a encaixante.

Esta associação foi interpretada como originada a partir de alojamento raso do granitóide gerando uma anomalia geotérmica, que, por sua vez, propiciou a circulação de água de formação e/ou meteórica. Fluxos de água em direção à câmara magmática e participando de processos de concentração mineral são propostos em modelos clássicos de mineralizações na literatura como o de PLANT et alii (1983). É possível que durante os estágios hidrotermais ocorreu a formação de V.G.Q. originados pela circulação de águas meteóricas e/ou de formação em zonas permeáveis, como as fraturas e contatos geológicos.

Podemos supor que, ao menos durante os eventos magmáticos anteriormente mencionados, se procedeu à circulação de fluidos em células convectivas as quais originaram V.G.Q. e possíveis mineralizações hidrotermais associadas. Provavelmente, a formação de V.G.Q. também ocorreu em períodos geológicos mais antigos e, devido ao efeito de metamorfismo regional, sua origem hidrotermal esteja mascarada, aflorando atualmente como cristas de quartzito.

\section{CONCLUSÕES E RECOMENDAÇÕES}

Os trabalhos realizados permitiram estabelecer claramente uma associação espacial e sugerir uma dependência genética comum entre os V.G.Q. e concentrações minerais hidrotermais, nos granitóides do Maciço Catas Altas. Esta associação possibilita a utilização destes veios como guias prospectivos, em outros granitóides do referido maciço, ainda não "monitorados" por este guia ou sua utilização em áreas geológicas análogas. 
Rev. IG, São Paulo, 7(1/2):11-16, jan./dez. 1986

MODELO DE POSSÍVEIS SITUAÇŌES DE GERAÇĀO DE VEIOS EPIGENÉTICOS RELACIONADO AO MAGMATISMO ALCALINO MESOZÓICO.

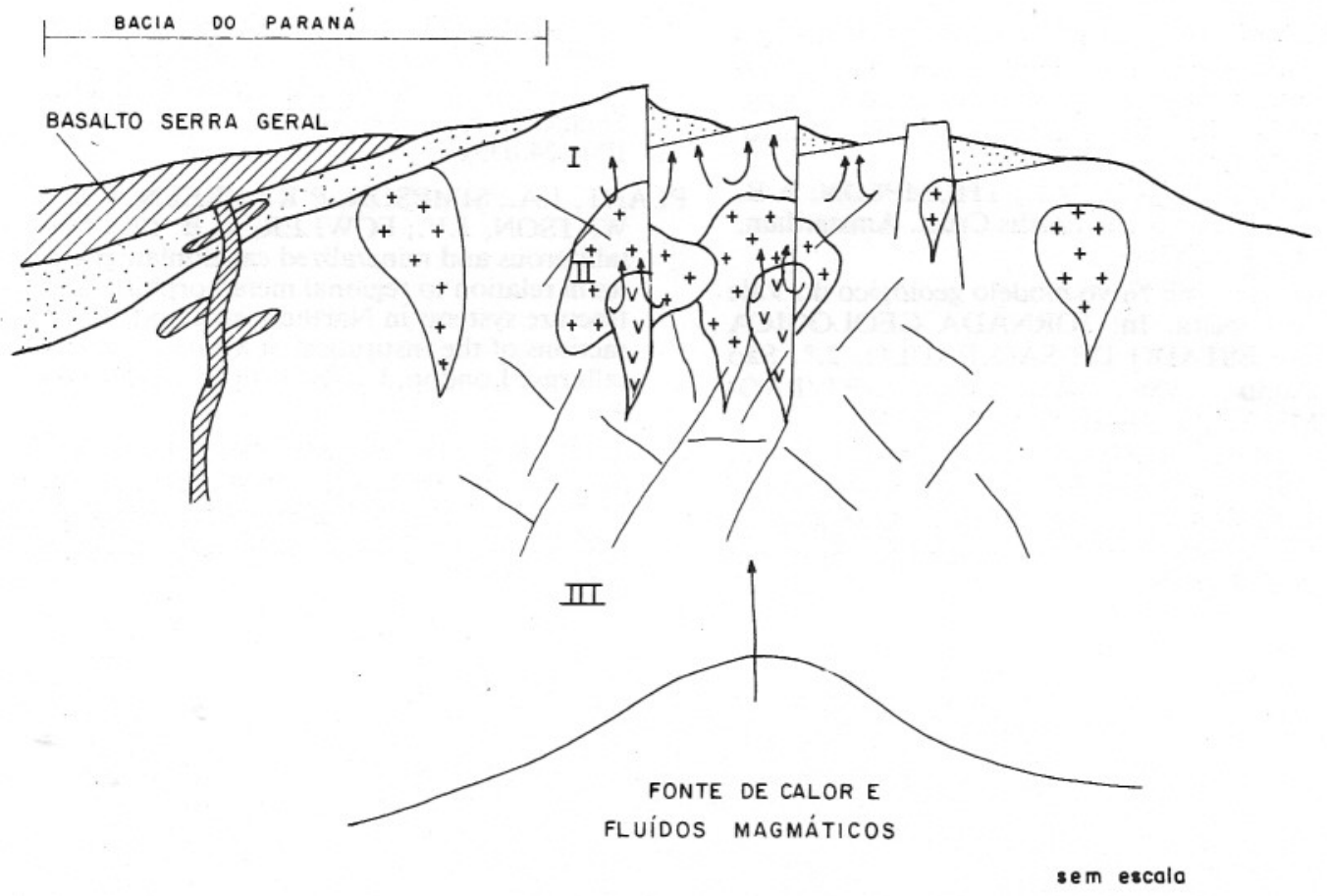

\section{LEGENDA}

$v_{v} v_{v}$ Intrusivas alcalinas e complexos carbonitíticos mesozóicos

$++_{+}^{+} \quad$ Gronitóides

1 Células de convecçāo

FIGURA- 2 
No estágio de conhecimento atual, são recomendados estudos laboratoriais (inclusões fluidas e geoquímica de elementos-traço) e de campo de detalhe, de modo a propiciar um melhor entendimento das relações genéticas entre as mineralizações e os veios gigantes ou a identificação de superposição de eventos metalogenéticos distintos.

\section{AGRADECIMENTO}

Agradeço ao colega Rubens Borges da Silva, geólogo, pelas críticas e sugestões apresentadas durante a elaboração deste trabalho.

\section{REFERÊNCIAS BIBLIOGRÁFICAS}

DARDENE, M. A. \& SAVI, C. N. 1984 Geologia e geoquímica dos filões de fluorita, segunda linha Torrens e Cocal - SC. Revista Brasileira de Geociências, São Paulo, 14(2):120-127.

FYFE, W.S.; PRICE, N.J.; THOMPSON, A.B. 1978 Fluids in the Earths Crust. Amsterdam, Elsevier. 383p.

HASUI, Y. 1986 Novo modelo geológico do Vale do Ribeira. In: JORNADA GEOLÓGICA DO ESTADO DE SÃO PAULO, 2. ${ }^{\circ}$, São Paulo, 1986. São Paulo, IPT/PRÓMINÉRIO. (Relatório IPT, 23.742).

IPT - INSTITUTO DE PESQUISÁS TECNOLÓGICAS DO ESTADO DE'SÃO PAULO. 1984 Fluorita: potencialidade geológica no Estádo de São Paulo - Fase I. (Relatório IPT, 21.266).
IPT - INSTITUTO DE PESQUISAS TECNOLÓGICAS DO ESTADO DE SÃO PAULO. 1986 Fluorita: potencialidade geológica no Estado de São Paulo - Fase II. (Relatório IPT, 24.039).

PLANT, J.A.; SIMPSON, P.R.; GREEN, P.M.; WATSON, J.V.; FOWLER, M.B. 1983 Metalliferous and mineralized caledonian granites in relation to regional metamorphism and fracture systems in Northern scotland. Transactions of the Institution of Mining and Metallurgy, London, United Kingdom (92B):3342.

SILLITOE, R. H. 1977 Metallic mineralization of filiated to subaerial volcanism: a review. In: VOLCANIC PROCESSES IN ORE GENESIS. London, Geological Society. (Special. Publication, 7). 